\title{
Application of Analog Inverter on Machine Tool
}

\author{
Xiaojing Liu \\ Dalian Engineering Consultation Center \\ Dalian, China \\ e-mail: dlliuxiaojing@163.com
}

\begin{abstract}
The paper introduces a method that make use of made in our country analog inverter \& spindle motor replace imports Digital Spindle drive \& spindle motor. Taking the DASEN16i CNC for example, dispose our country analog inverter \& spindle motor, increase spindle position control software, using CNC spindle Analog interface connection to the inverter, design circuit of electric connection, design ladder diagram of spindle speed, spindle gear change, orientation, rigid tapping etc. Final in Machining center complete use of made in our country analog inverter \& spindle motor replace imports Digital Spindle drive \& spindle motor, and vertical machining center of Dalian Machine Tool Group Corp achieve commodity.
\end{abstract}

Keywords-component; Machining center; Spindle driver; Analog inverter; Functional parts; Spindle speed

\section{INTRODUCTION}

Analog AC inverter is a kind of speed control device. In the past, it is applied on low-grade CNC lathe, and rarely on high-end $\mathrm{CNC}$ machine tools because of the restrictions by the function. That the main reason is that the frequency converter control speed only, without position control function, lack of the function of spindledirecting and rigid Tapping which is required by ATC machining centers. After years of low-end development, China's CNC machine tool industry is now an urgent need to enhance the competitiveness of industry products and take the high road of development. For this purpose, after a certain design, the parameters of inverter and numerical control system has a servo spindle drive functions of highend CNC machine tools and especially the machining centers, to achieve high-end CNC machine tools feature package. It provides machining center with a new configuration which has the functions of spindle speed control, automatic tool change spindle orientation and rigidity required for tapping through localization A1000 universal AC drive writing ladder program of variable program controller after reasonable parameter settings and domestic CNC system connection. It led to the development of the market of domestic CNC machine tools $、 \mathrm{CNC}$ systems and related features and provide a good condition for domestic machine tool market expansion. It has strategic significance of the times to achieve the goals of China's high profile main features of CNC machine tools based on domestic by 2020、 high profile CNC machine tools which is needed for marine, automotive and power generation equipment manufacturers and basic manufacturing equipment to achieve $80 \%$ localization and complete system of domestic $\mathrm{NC}$.

\section{MACHINING CENTER AC ANALOG CONVERTER CONFIGURATION}

First, domestic production currently Yaskawa A1000, Delta VFD-VE series AC analog converter are needed to focus on, and transmit signals between that and $\mathrm{CNC}$ systems is by correspond to specific endpoints and analog voltage mode, and can support connections with the current home and abroad with the simulation, two kinds of digital output spindle CNC system; Such as Japan FANUC, MITSUBISHI, Germany SIEMENS, domestic Omori, wide number, Huazhong CNC system with spindle analog output interface, there would be no obstacle to the control signal connection between such systems and numerical simulation of the inverter [1-4].

Secondly, the inverter is merely a simulation speed controlling device with no position control function. When machining center tool change, spindle orientation is required; when rigid tapping, spindle (rotation axis) and Zaxis (linear axis) position interpolated motion is required, those are related to the spindle position control function. Therefore, it needs to adjust and set the control parameters of the spindle in the numerical control system and analog converter, Install the encoder on the spindle and constitute spindle position, speed and current closed loop with analog converter, the CNC spindle feedback interface CNSP [5,6].

The block diagram of machining center spindle control device configured by analog converter is shown in Fig .1. This device is composed by CNC system DASEN16i (4axis), analog inverter A1000 (11/15 kW), spindle motor $(7.5 / 11 \mathrm{~kW})$ and position encoder (1024P). Owning to spindle control function is just about $\mathrm{z}$-axis, other axis are not marked in diagram.

Parameters in diagram:

$\mathrm{S} \times \times \times \times \times$ : spindle rotation speed command.

M3-5:spindle natural rotation/inversion/stop command.

M19/18: spindle directional/ remove command.

M843/844/845: spindle rigid tapping natural rotation/ inversion/ remove command.

PLC: Programmable Logic Controller.

Ps: spindle position instruction.

Pz: $\mathrm{z}$-axis position instruction.

ps: spindle position command.

Fs: spindle position feedback.

Pz: z-axis position instruction.

pz: $\mathrm{z}$-axis position command.

Fz: z-axis position feedback. 
CNSC: spindle output analog interface.

CNSP: spindle input feedback interface.

CNSV3: z-axis output digital interface.

CNFB3: z-axis input feedback interface.

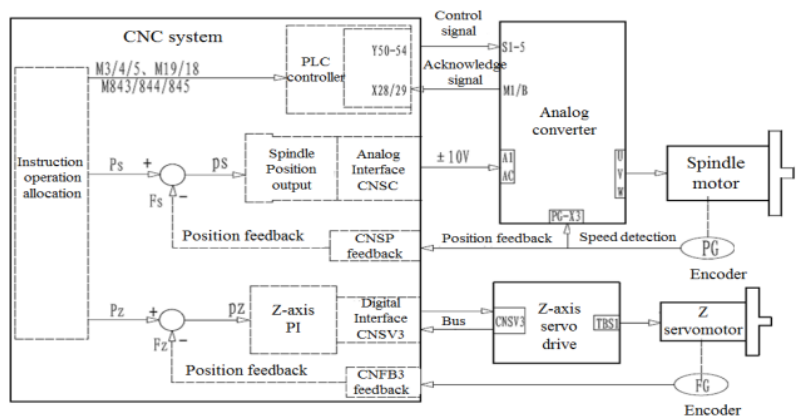

Figure 1. The block diagram of machining center spindle control device configured by analog converter

\section{CONNECTION CIRCUIT IS DIVIDED INTO THE FOLLOWING FOUR GROUPS MAJOR LOOP}

\section{A. Control loop of inverter mode}

Connect the terminal $(1,2,3,4,5)$ of $\mathrm{CNC}$ system programmable controller output interface $\mathrm{CN} 11$ with analog inverter input interface (S1, S2, S3, S4, S5) one to one correspondingly. Transport spindle control signal spindle enabling (Y50), gain switch (Y51), emergency stop (Y52), alarm reset (Y53), accelerate and slow down switch (Y54) to the input interface of analog inverter, and control the mode of analog inverter and spindle motor [7].

\section{B. Answer loop of analog inverter mode}

Connect the inverter output terminal MB, M1 with the terminal $(1,2)$ of PLC input interface CN6 correspondingly. Transport the spindle alarm and the state answer of spindle operation to PLC.

\section{Spindle analog input/ output interface}

Connect the spindle analog input/ output interface CNSC terminal $(2,1,9,10)$ of CNC system with the input/ output terminal (A1, AC, FM, AC) of analog inverter correspondingly. Transport the $\pm 10 \mathrm{~V}$ voltage output by spindle analog interface, the practical rotation speed of spindle motor and load $0 \sim 10 \mathrm{~V}$ voltage to analog inverter and $\mathrm{CNC}$ system respectively to control the natural/ inversion rotation, rotation angle, rotation speed, torque of analog inverter and the practical rotation speed and load factor of CNC system feedback spindle motor [8,9].

\section{Control loop of inverter mode}

Connect the terminal $(3,4,5,6,7,8,1,2)$ of spindle position encoder PG with analog inverter TB1 and the TB2 terminal (A+, A-, B+, B-, Z+, Z-, IP, IG) respectively, and then connect the terminal ( $\mathrm{SG}, \mathrm{AO}, \mathrm{IG}, \mathrm{BO}, \mathrm{IG}, \mathrm{ZO}, \mathrm{IG})$ of $\mathrm{TB} 2$ to the terminal $(1,11,12,13,14,9,10)$ of $\mathrm{CNC}$ system spindle position feedback interface CNSP. Transport the pulse generated by spindle encoder to analog inverter and then to CNC system to achieve the closedloop control of position, velocity and electricity [10].

\section{MACHINING CENTER SPINDLE CONTROL PROCESSES AND LADDER}

A. Spindle speed shift and control processes

Spindle speed shift and control processes are shown in Fig .2.

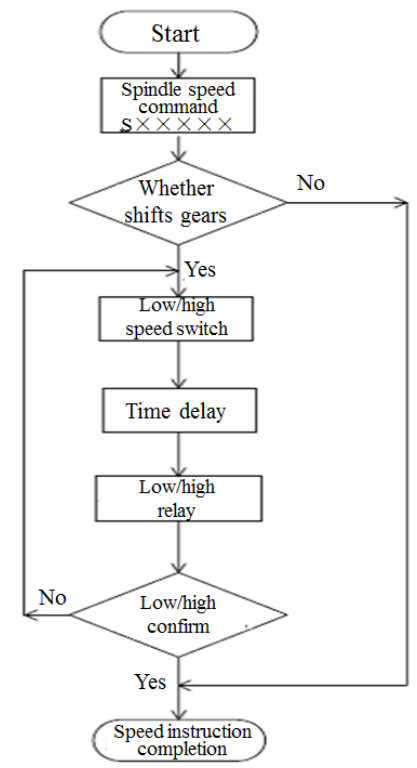

Figure 2. Spindle speed shift and control processes

\section{B. Tool change spindle orientation control flow}

Tool change spindle orientation control flow is shown in Fig .3.

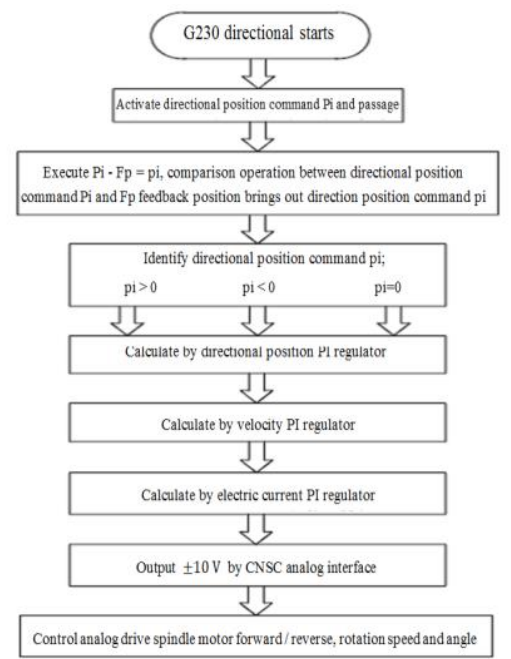

Figure 3. Tool change spindle orientation control flow

\section{The ladder of spindle machining center features configured by analog inverter}

The ladder of spindle machining center features configured by analog inverter is shown in Fig .4.

\section{CONCLUSION}

By adopting the above design of circuits and ladder, Yaskawa A1000 analog drive is configured in the highgrade machining centers (Delta VFD-VE, part domestic 
inverter can be applied), it not only reduces the manufacturing cost of machining centers, more important extends spindle machining center features a supporting channels, high-end CNC machine tools and gradually reduces dependence on foreign key features by that only speed control function analog, the spindle motor and the inverter system with $\mathrm{CNC}$ are all used in high-grade machining centers. Currently carried out experiments with machines assessment in the Dalian Machine Tool Group VDF-850D vertical machining center, performance indicators have reached the factory acceptance criteria, and has taken a solid step forward to achieve the 2020 highend $\mathrm{CNC}$ machine tools localization strategic objectives $[1,5,10]$.

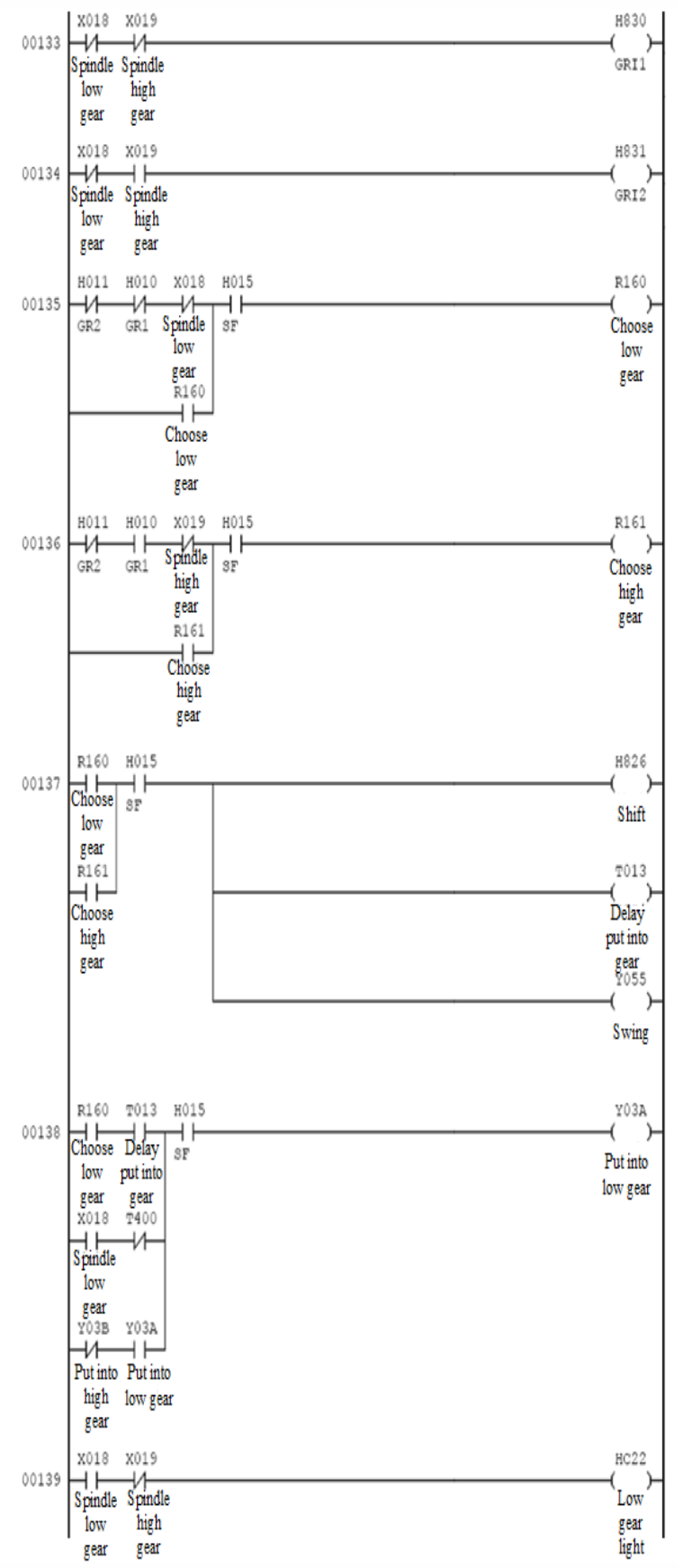

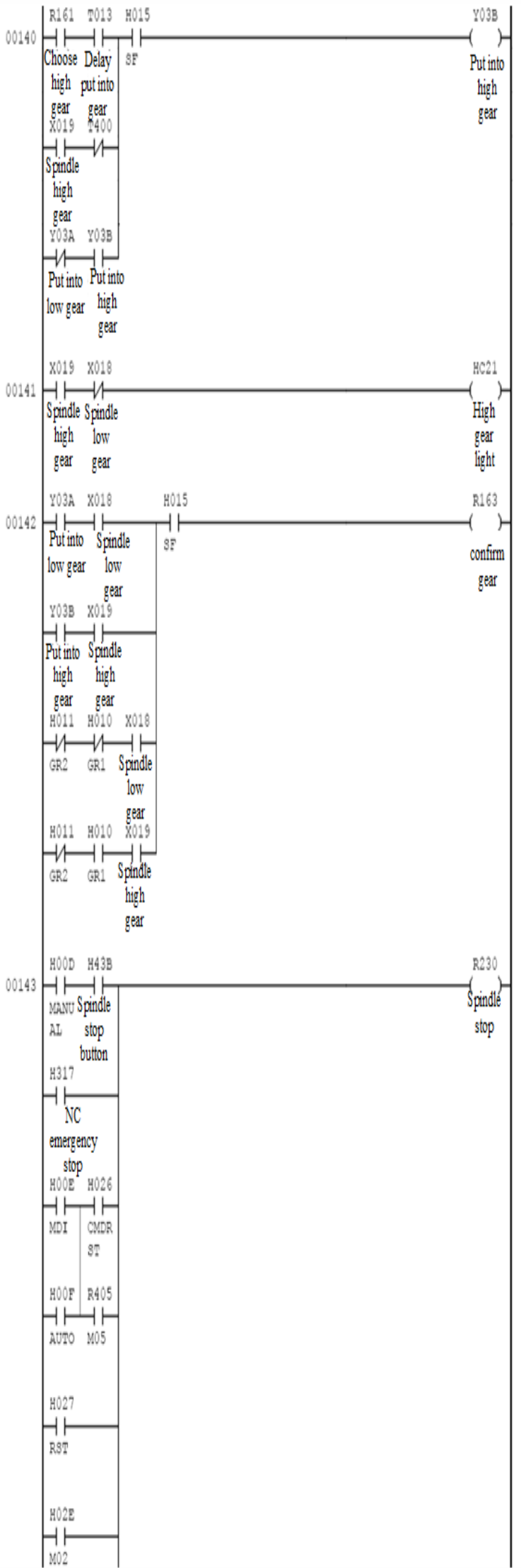



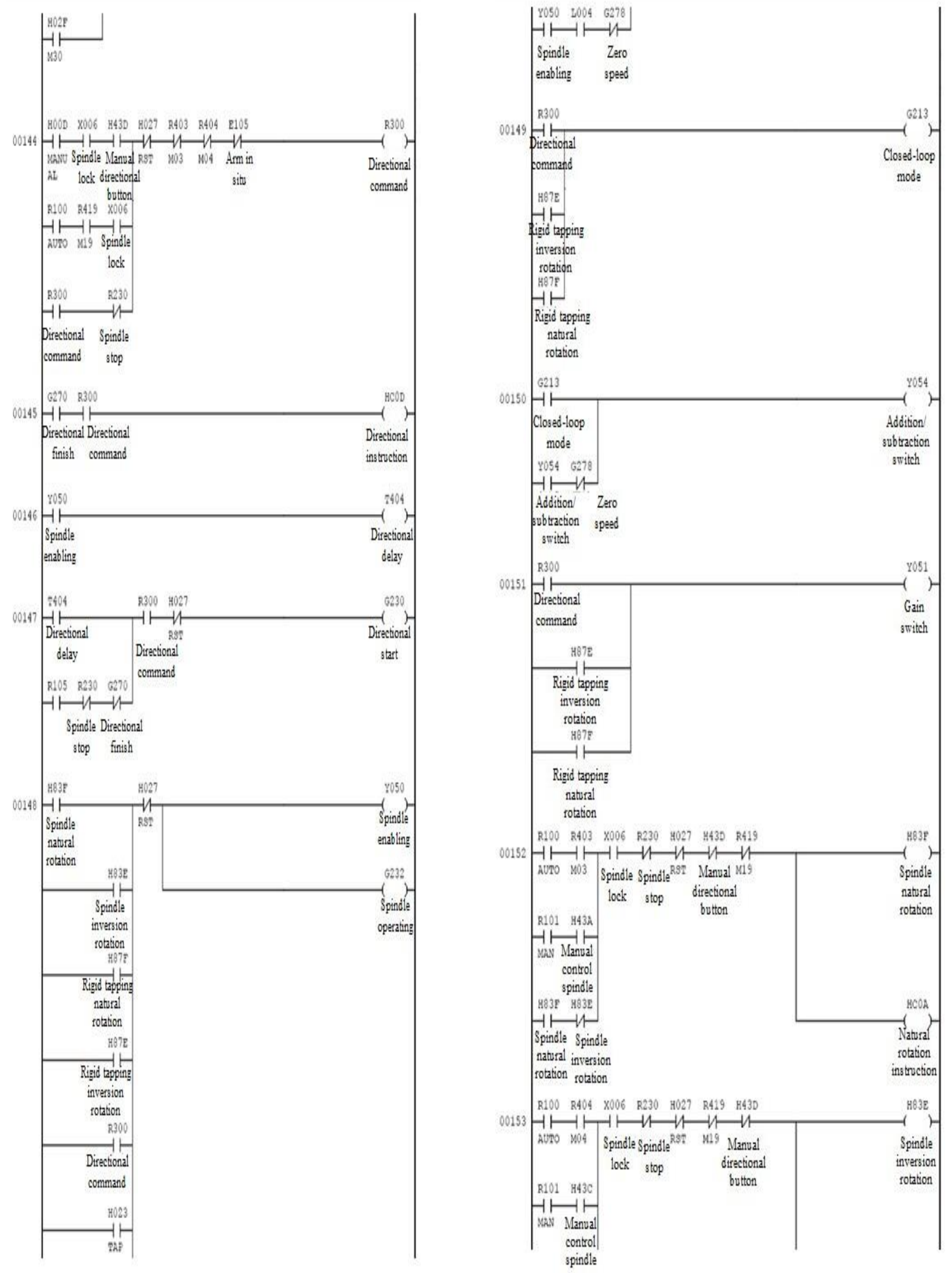


\section{REFERENCES}

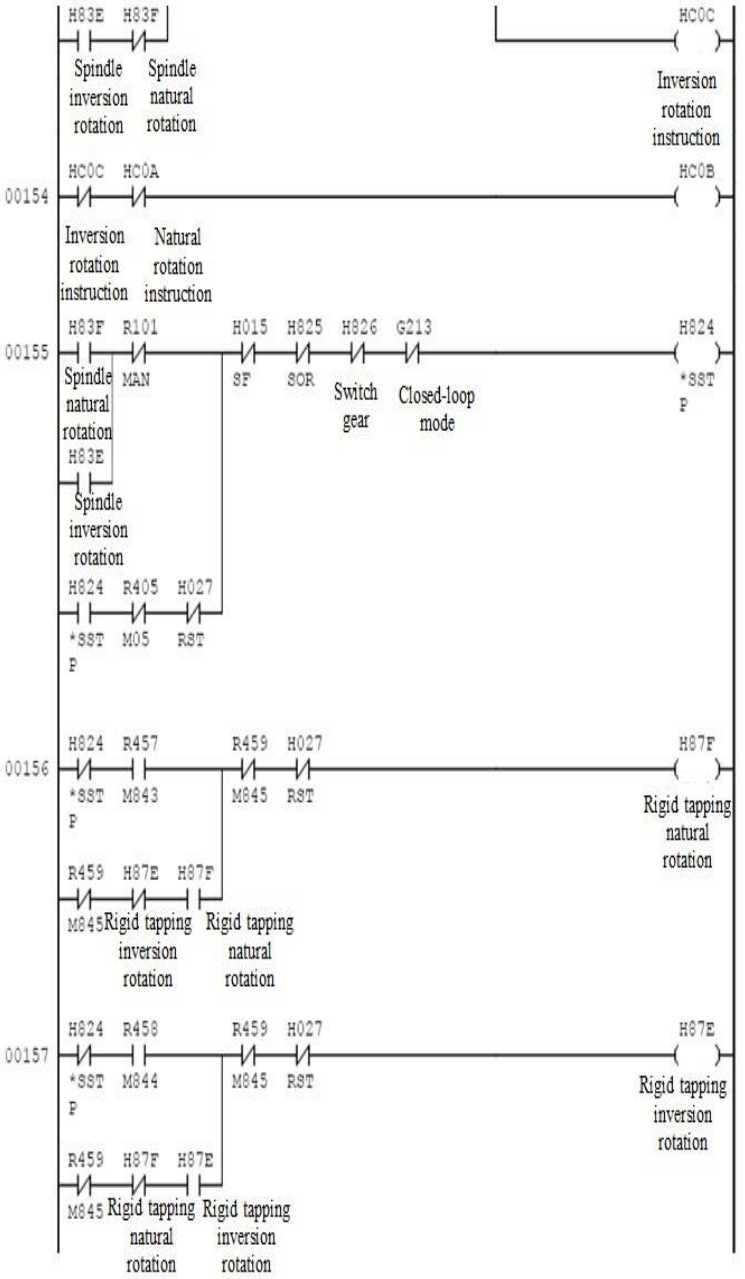

Figure 4. Rigid tapping control flow
[1] E. O'Meara, D. Stack, S. Phelan, et al, "Identification of an MLLA - GPS2 fusion as an oncogenic driver of undifferentiated spindle cell sarcoma in a child," Genes, Chromosomes and Cancer, Aug. 2014, pp. 991-998, doi: 10.1002/gcc.22208.

[2] T. Ishibashi, H. Fujimoto, S. Ishii, et al, "High-frequency-variation speed control of spindle motor for chatter vibration suppression in NC machine tools," American Control Conference (ACC), IEEE Jun. 2014, pp. 2172-2177, doi: 10.1109/ACC.2014.6858869.

[3] S. Walker, A. Thomas, G. Taylor, "Operation of the alula as an indicator of gear change in hoverflies," Journal of The Royal Society Interface, Apr. 2012, pp.1194-1207, doi: 10.1098/rsif.2011. 0617.

[4] C. Witherspoon, P. Zheng, M. Chmielus, et al, "Texture and training of magnetic shape memory foam," Acta Materialia, Apr. 2013, pp. 2113-2120, doi:10.1016/j.actamat.2012.12.032.

[5] E. Stefani, A. Gazin, "Instructional sequences in driving lessons: Mobile participants and the temporal and sequential organization of actions," Journal of Pragmatics, May. 2014, pp. 63-79, doi:10.1016/j.pragma.2013.08.020.

[6] J. Tamayo, R. Garcia, "Deformation, contact time, and phase contrast in tapping mode scanning force microscopy," Langmuir, Dec. 1996, PP. 4430-4435, doi: 10.1021/la9601891.

[7] G. Yahalom, E. Simon, R. Thorne, et al, "Hand rhythmic tapping and timing in Parkinson's disease," Parkinsonism \& related disorders, Mar. 2004, pp. 143-148, doi:10.1016/j.parkreldis.2003. 10.001 .

[8] J. Lu, H. Zou, L. Shen, et al, "Application of Adaptive Fuzzy-PID Control in Servo Spindle Rigid Tapping," Advanced Materials Research, 2011, pp. 1477-1481, doi: 10.4028/www.scientific.net/ AMR.301-303.1477.

[9] G. Lee, H. Zandong, J. Lee, "Automatic generation of ladder diagram with control Petri net," Journal of Intelligent Manufacturing, Apr. 2004, pp: 245-252, doi: 10.1023/B:JIMS 0000018036.84607 .37 .

[10] J. Quezada, J. Medina, E. Flores, et al, "Formal design methodology for transforming ladder diagram to Petri nets," The International Journal of Advanced Manufacturing Technology, Jul. 2014, pp: 821-836, doi: 10.1007/s00170-014-5715-9. 